\title{
CARLOS ALBERTO FARACO E FRANCISCO EDUARDO VIEIRA (Orgs.). 2016. Gramáticas brasileiras: com a palavra, os leitores. São Paulo: Parábola, 336 pp. ISBN 978-85-7934-121-2
}

\author{
MARIZE MATTOS DALL'AGLIO-HATTNHER ${ }^{1}$
}

${ }^{1}$ Universidade Estadual Paulista/CNPq. marize@ibilce.unesp.br

Falar sobre o livro Gramáticas brasileiras: com a palavra, os leitores implica, naturalmente, falar sobre a obra que Ihe serviu de motivação. Após a realização, em 2013, de um bem sucedido encontro dos principais gramáticos contemporâneos da língua portuguesa em uma mesa-redonda realizada durante o IV Simpósio Mundial de Estudos de Língua Portuguesa, Maria Helena de Moura Neves e Vânia Casseb Galvão (2014) organizaram o livro Gramáticas contemporâneas do português: com a palavra, os autores, reunindo as contribuições de Evanildo Bechara, Maria Helena Mira Mateus, Mário Perini, Maria Helena de Moura Neves, José Carlos Azeredo, Ataliba T. de Castilho e Marcos Bagno. A cada um desses autores foi pedido que completasse a frase "Eu defino minha gramática como...". Tanto na mesa-redonda quanto na obra organizada por Neves e Galvão, dois comentaristas, Marli Quadros Leite e Francisco Platão Savioli, analisaram a contribuição dessas gramáticas em dois âmbitos diferentes: a história recente das ideias linguísticas e o ensino da língua portuguesa.

Como apontam Faraco e Vieira, organizadores da obra aqui resenhada, uma vez que a palavra dos autores já havia sido registrada no evento e na publicação posterior, "surgiu a ideia de organizar outro livro reunindo agora textos que dessem voz a leitores especialistas das obras gramaticais, criando contrapontos críticos às narrativas dos gramáticos" (p. 8). Com alguns ajustes em relação à obra organizada por Neves e Galvão - a exclusão da Gramática da língua portuguesa, escrita em co-autoria por Maria Helena Mira Mateus e oito linguistas portuguesas, e a inclusão da Gramática da língua portuguesa padrão, escrita por Amini Boainain Hauy e publicada após a realização do SIMELP - a coletânea de textos propõe-se a estabelecer o contra-ponto autor-leitor de sete obras gramaticais: Bechara (1999), Neves (2000, 2011), Azeredo (2008), Perini (2010), Castilho (2010), Bagno (2012) e Hauy (2014).

Embora a proposta dos organizadores tenha sido a de apresentar, em cada capítulo, os problemas específicos de cada gramática identificados pelos leitores especialistas, considero como contribuição maior dessa obra a discussão de 
"algumas das questões mais gerais que atravessam o fazer gramatical" (p. 16). Em vários momentos, a análise das gramáticas parece ser apenas o pano de fundo para a reflexão sobre problemas teóricos, metodológicos e ideológicos envolvidos na elaboração de gramáticas.

Assim é que, no capítulo 1, intitulado "Gramatização brasileira contemporânea do português: novos paradigmas?", Francisco Eduardo Vieira faz um interessante apanhado da história da gramática, desde os gramáticos alexandrinos da Antiguidade aos gramáticos normativos de hoje, enfocando o escopo do que ele denomina de "paradigma tradicional de gramatização", um fazer gramatical a partir do modelo gramatical greco-latino. Na reconstrução desse percurso histórico da produção de gramáticas, Vieira discute, entre outros aspectos, a tradição prescritivo-normativa, a terminologia gramatical, os critérios de classificação e o português no/do Brasil.

Ao tratar especificamente das gramáticas de Azeredo (2008), Perini (2010) e Bagno (2012), Vieira analisa "a) as demandas e os propósitos sociais de tais obras; b) seu perfil teórico-metodológico; c) seu arcabouço descritivo, categorial e conceitual; d) os aspectos morfossintáticos da língua gramatizada por elas" (p. 42), mostrando que, em todos esses aspectos, as gramáticas brasileiras contemporâneas oscilam entre movimentos de ruptura e linhas de continuidade em relação ao paradigma tradicional.

No capítulo 2, "Gramática Houaiss: o impossível equilíbrio entre descrição e prescrição", Xoán Carlos Lagares faz uma reflexão sobre um aspecto específico da Gramática Houaiss da língua portuguesa, escrita por José Carlos Azeredo, discutindo "o modo como nela se articula a difícil distinção entre descrição e prescrição, e sobre a ideia de "português brasileiro" que dela emerge" (p. 71). Embora o foco seja a gramática de Azeredo, a crítica de Lagares sobre a ausência de uma distinção sociolinguística entre norma culta e norma padrão aplica-se igualmente a outras gramáticas que se apresentam como descritivas: ao excluir formas consideradas como próprias do padrão "informal e oral" e da "fala espontânea", a gramática de Azeredo contribui "para legitimar determinada norma prescritiva, numa linha tênue que conduz, não sem tensões, à norma da tradição conservadora da língua portuguesa" (p. 81).

No capítulo 3, "Gramática pedagógica do português brasileiro: apontamentos portugueses", Fernando Venâncio analisa, sob um viés específico, a Gramática Pedagógica do português brasileiro (2012), escrita por Marcos Bagno. Ao examinar as inúmeras considerações sobre o português europeu que permeiam essa gramática, Venâncio deixa claro o que considera ser uma perigosa simplificação, que acaba por resultar em um "estranho paradoxo": "Sublinhando a inovação gramatical como marca brasileira, sugerindo que o português europeu se rege monotonamente pela velha cartilha, Marcos Bagno corre o risco de, afinal, ratificar a imagem abusiva, idealizadora, e factualmente oportunista que os "puristas empedernidos" brasileiros alimentam" (p. 94). Depois de apresentar várias aproximações entre as mudanças ocorridas no português brasileiro e no português europeu, Venâncio demonstra como o 
português europeu transformou-se, na gramática de Bagno, em um "interlocutor ausente, demasiadamente ausente. $O$ risco é o de sugerir-se como exclusivo do português brasileiro tudo quanto circunstanciadamente se expõe, já para além daquilo que explicitamente assim se declara" (p. 106). Por fim, Venâncio pondera que "uma abordagem sistematicamente contrastiva poderia ser, assim, opção mais vantajosa, ao cotejar padrões de expressão espontânea cuidada, tanto falada como escrita, e explorando alguns outros domínios gramaticalmente irredutíveis" (p. 107).

A Moderna gramática portuguesa, de Evanildo Bechara, é analisada por Roberto Mulinacci no capítulo 04, intitulado "Moderna gramática portuguesa: habemus grammaticam?". Sem desconsiderar o papel fundamental da gramática de Bechara, que atua como um divisor de águas entre o prescritivismo clássico e o tratamento mais científico dos assuntos linguísticos, Mulinacci aponta um conjunto de limitações dessa obra. Entre as razões para essas limitações, Mulinacci destaca i) a incongruência entre as premissas teórico-metodológicas e a análise dos conteúdos gramaticas; ii) a opção por uma língua tida como unitária entre Brasil e Portugal; iii) a opção por uma atitude prescritiva, ainda que moderada; iv) a opção por exemplos esmagadoramente literários e não contemporâneos. Tomando o cuidado de ressalvar que sua análise desconsidera as muitas partes "mais bem realizadas e convincentes do livro" (p. 146) e que, portanto, sua análise não resume um juízo de valor sobre a obra, Mulinacci deixa claro que o objetivo de seu capítulo é o de submeter a Moderna gramática brasileira, publicada em sua $37^{a}$. edição em 1999, ao "confronto com as novas concepções gramaticais surgidas ao longo destes últimos quinze anos para verificar se e quanto dos pressupostos teóricos em que ela se assenta continuam válidos e defensáveis ainda hoje" (p. 146).

O capítulo 5, intitulado "Nova gramática do português brasileiro: um olhar sociolinguístico", traz a análise de Ana Maria Stahl Zilles sobre a gramática de Ataliba T. de Castilho (2010). Quatro perguntas nortearam a análise de Zilles: A obra pode, de fato, ser chamada de gramática? Quem pode se beneficiar da leitura ou da consulta a esta obra? Qual o objetivo do autor ao propor esta gramática? Qual o objeto de estudo dessa gramática? Ao longo do capítulo, a análise de Zilles pontua a Gramática do português brasileiro como mais do que um gramática, como um "compêndio de linguística" em que a análise gramatical combina características de uma gramática descritiva e de uma gramática histórica. Destinada originalmente por Castilho a professores de ensino médio, alunos de curso superior, professores universitários de linguística geral e de linguística do português brasileiro, Zilles entende que a obra seria adequada, também, para professores e pesquisadores de aquisição da linguagem e de fonoaudiologia, e para professores e pesquisadores de português como língua adicional. É na análise do objetivo do autor e do objeto da gramática que se encontra a contribuição maior deste capítulo. Ao discutir "a concepção unitária e homogênea de português brasileiro" proposta por Castilho e argumentar "a favor da necessidade de distinguirmos, desde uma perspectiva sócio-histórica, a diversidade de normas cultas e populares existentes em nosso país e, consequentemente, a existência de diferentes gramáticas" (p. 183), Zilles 
retoma uma preocupação que tem permeado, em maior ou menor grau, todos os capítulos da obra aqui resenhada.

O capítulo 6 traz a análise de uma gramática não incluída na obra de Neves e Galvão, que deu voz aos autores, a Gramática da língua portuguesa padrão, de Amini Boainain Hauy (2014). Aqui também se repete um percurso comum a outros capítulos, que acaba por fazer da obra organizada por Faraco e Vieira uma coletânea de análises sobre a tradição gramatical no Brasil e sobre questões sócio-históricas do português brasileiro que têm, muitas vezes, apenas como pano de fundo a análise das gramáticas arroladas. Não é diferente no capítulo escrito por Marcelo Alessandro Lima dos Anjos, que analisa a herança grecolatina na tradição gramatical do ocidente, os legados de Fernão de Oliveira e João de Barros, e a realidade multifacetada do português do Brasil. Na análise da gramática de Hauy, que Anjos faz em contraponto com outras gramáticas aqui comentadas, algumas falhas são salientadas: as restrições do corpus, composto por obras literárias e textos oficiais, a não distinção entre norma culta e norma padrão, o não aproveitamento das contribuições da linguística para os componentes fonético e fonológico e inconsistências na definição de algumas classes de palavras, vozes verbais, regência verbal e colocação pronominal.

Como conclusão, Anjos situa a gramática de Hauy "em um claro movimento de continuidade com a tradição gramatical greco-romana". Curiosamente, foram justamente as críticas a essa tradição, explicitadas por Hauy (1983) na conhecida obra Da necessidade de uma gramática-padrão da língua portuguesa, que motivaram Faraco e Vieira a incluir a gramática de Hauy no volume organizado por eles, considerando "imperioso investigar quanto deste seu trabalho responde às críticas e ao desiderato que Hauy formulara em seu livro anterior" (p.10).

A obra Gramática de usos do português, de Maria Helena de Moura Neves (2000), é analisada em dois capítulos. Segundo os organizadores, motivos meramente circunstanciais resultaram na análise de Ana Lima, que traz o subtítulo "metalinguagem em função" (capítulo 7) e na de Maria Filomena Gonçalves, que traz o subtítulo "usos na gramática e gramática dos usos" (capítulo 8). Quaisquer que tenham sido os motivos, o fato é que as duas análises se somam, pontuando em uníssono as qualidades teóricometodológicas da gramática de Neves.

Ana Lima destaca a concepção mais especializada de gramática adotada por Neves, assim sintetizada: "'gramática' é o aparato acionado pelo falante/escritor com vistas a, na atividade linguística, produzir sentidos. Esse acionamento obriga o usuário a um 'cálculo' do qual resultam escolhas adequadas a seus propósitos comunicativos, em uma dada situação de interação verbal." (p. 219).

Condizente com essa conceituação, a gramática de Neves assenta-se em princípios funcionalistas e, ao colocar os usos linguísticos como seu objeto de análise, assume posição diferenciada em relação a outros manuais de gramática, utilizando-se de um conjunto de dados empíricos constantes em um vastíssimo 
corpus de textos escritos de diferentes gêneros. Também decorre desses princípios teóricos a escolha de Neves por organizar o exame do funcionamento da língua a partir de processos (predicações, referenciações, indefinições, junções, modalizações), o que acaba por resultar em uma organização bastante consistente, mas de difícil compreensão para o leitor comum ou para o estudioso da língua não familiarizado com a teoria funcionalista subjacente, como aponta Lima.

A existência de algumas fragilidades na exemplificação por vezes insuficiente para comprovar as explicações, na impossibilidade de o leitor relacionar os gêneros analisados com os usos descritos, e na consideração da heterogeneidade linguística são alguns dos pontos críticos apontados por Lima, que, no entanto, salienta o inabalável "lugar de destaque que a gramática de Neves ocupa "como importante instrumento da gramaticografia brasileira" ( $p$. 235).

A singularidade da gramática de Neves no contexto da produção gramatical do português é também apontada por Maria Filomena Gonçalves, no capítulo 8, que justifica essa avaliação pelo fato de i) a gramática visar os usos comuns documentados em um vasto corpus; ii) sua análise partir das classes de palavras em direção à identificação da sua multifuncionalidade em vários níveis e processos; iii) e, mesmo se afastando de uma prescrição, sua análise não deixar de atender "nem à tradição da qual provêm as referidas classes de palavras, nem à ideia de norma como aquilo que é "normal" no uso da língua (p. 264). As fragilidades apontadas por Gonçalves coincidem com aquelas apontadas por Lima: as limitações das bases de dados, a complexidade das informações e da metalinguagem apresentadas, que nem sempre estão ao alcance do público-alvo pretendido por Neves.

Por fim, no capítulo 9, José Borges Neto analisa a Gramática do português brasileiro, de Mário Alberto Perini (2010). Borges Neto apresenta a gramática de Perini como uma gramática descritiva da língua falada no Brasil que se afasta consideravelmente do modelo greco-latino. Diferencia-se também das outras gramáticas pela sua finalidade e pelo tratamento dos assuntos. Essas duas diferenças decorrem de uma posição teórico-metodológica claramente assumida por Perini: o fato de a gramática ser considerada uma disciplina científica e o fato de o autor não assumir nenhuma linha teórica específica para construir as explicações oferecidas em sua gramática. Como explica Borges Neto, essa posição justifica-se pela intenção do autor de "levar o leitor a reflexões sobre a gramática da língua portuguesa falada" (p. 271). Ou ainda, "de promover junto aos alunos uma reflexão científica sobre os fatos da língua" (p. 275). É sob essa especificidade de propósitos que a gramática de Perini deve ser analisada, e é assim que Borges Neto realiza sua análise. Os aspectos problemáticos da gramática apontados pelo analista - a necessidade de um maior cuidado na definição das classes de palavras, a delimitação da variedade "padrão" do português brasileiro, o uso protocolar da gramática tradicional - não chegam a invalidar a proposta de Perini. Na avaliação de Borges Neto, "discordar das 
descrições porque inadequadas aos fatos e propor descrições alternativas, para os fatos "revistos", é parte fundamental da alfabetização científica" (p. 288).

Encerra o livro um capítulo escrito por Faraco e Vieira, que apontam a diversidade de conteúdo, de abordagem e de escopo das sete gramáticas analisadas. Mesmo essa diversidade tornando natural a pergunta sobre o que é, afinal, uma gramática, os organizadores dessa obra que dá voz a leitores especialistas conseguem identificar algumas direções convergentes e muitas divergentes no conjunto de gramáticas analisadas. E é no apanhado dessas direções que reside o aspecto mais profícuo da obra aqui resenhada: o de identificar, como já se disse, algumas das questões mais gerais inerentes ao fazer gramatical, para além dos problemas específicos de cada gramática analisada.

Embora os organizadores tenham pretendido que esta obra fosse lida "tanto por aqueles já familiarizados com as gramáticas aqui em tela [...] quanto por aqueles que desconhecem boa parte desse rico e recente acerto de gramáticas brasileiras" ( $p .17)$, o ideal seria conhecê-las, de forma a melhor entender as diferentes propostas. Na impossibilidade, recomendo, como leitura prévia que instrumentaliza o leitor para assumir a sua própria voz, a leitura da obra Gramáticas contemporâneas do português: com a palavra, os autores.

\section{REFERÊNCIAS BIBLIOGRÁFICAS}

Azeredo, José Carlos de. 2008. Gramática Houaiss da língua portuguesa. São Paulo, Publifolha.

Bagno, Marcos. 2012. Gramática pedagógica do português brasileiro. São Paulo, Parábola.

Bechara, Evanildo. 1999. Moderna gramática do português contemporâneo. 37 ed. Rio de Janeiro, Lucerna.

Castilho, Ataliba T. de. 2010. Nova gramática do português brasileiro. São Paulo, Contexto.

Hauy, Amini Boainain. 1983. Da necessidade de uma gramática-padrão da língua portuguesa. São Paulo, Ática.

. 2014. Gramática da língua portuguesa padrão. São Paulo, Edusp.

Mateus, M. H. et al. 2003. Gramática da Língua Portuguesa. 7 ed. revista e aumentada. Lisboa, Caminho.

Neves, Maria Helena de Moura. 2000. Gramática de usos do português. São Paulo, Ed. UNESP.

. 2011. Gramática de usos do português. $2^{a}$ ed. revisada. São Paulo, Editora UNESP.

Neves, Maria Helena de Moura e Vânia Cristina Casseb Galvão (Orgs.). 2014. Gramáticas contemporâneas do português: com a palavra, os autores. São Paulo, Parábola.

Perini, Mário A. 2010. Gramática do português brasileiro. São Paulo, Parábola. 
